\section{Severe esophageal burn after transesophageal pacing}
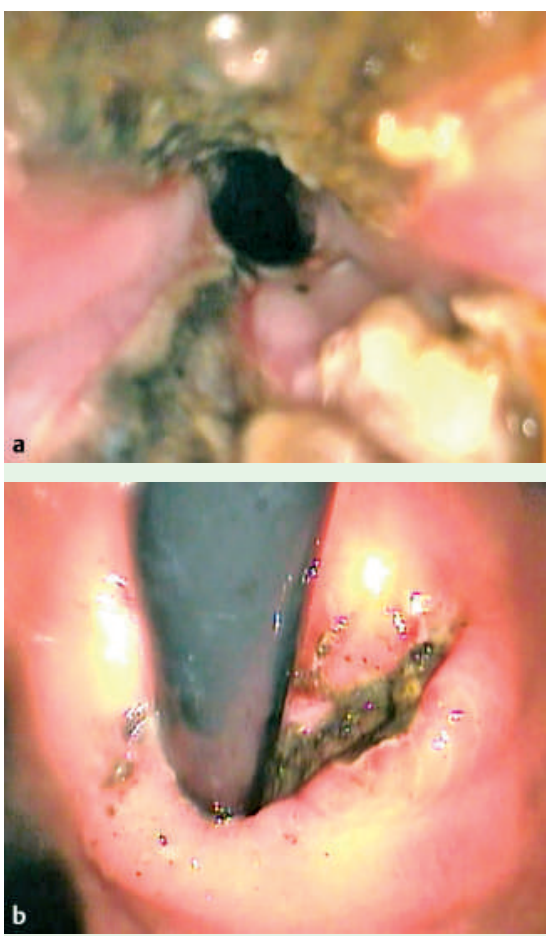

Fig. 1 Endoscopic views of the tissue necrosis in the esophagus (a), reaching down into the cardia (b), 6 hours after pacing.

A 13-year-old girl with tachycardia and a 3-week history of fatigue and headaches was admitted with suspected myocarditis. Echocardiography showed a dilated left ventricle with a shortening fraction of $12 \%$. Electrocardiography revealed ectopic atrial tachycardia, with a heart rate of 200 beats per minute. Cardioversion was performed to terminate the tachycardia, but this was unsuccessful. Intravenous amiodarone was started, but within hours the girl had deteriorated. Verapamil and beta blockers were not suitable because of their negative inotropic effects, and so a transesophageal electrode catheter was placed under fluoroscopic guidance. Rapid atrial pacing (320/minute, $20 \mathrm{~mA}$ ) resulted in atrioventricular block and the ventricular rate fell to 160 beats per minte. The amiodarone treatment was continued and sinus rhythm was achieved after 18 hours, when atrial pacing was stopped.

Esophagogastroduodenoscopy was performed 6 hours after the transesophageal pacing was stopped: areas of deep tissue

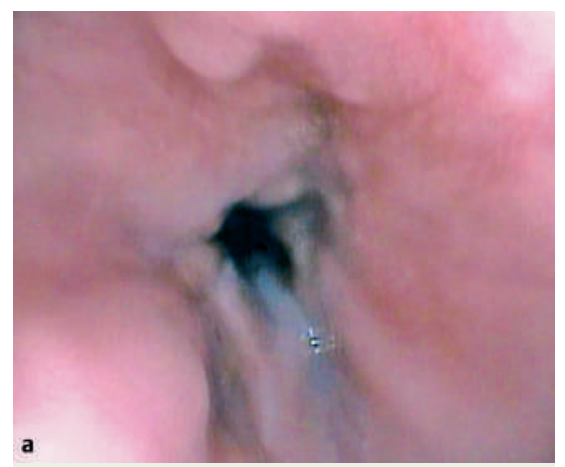

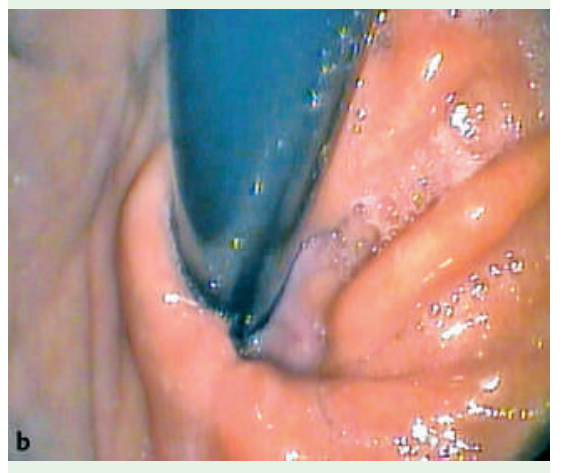

Fig. 2 Endoscopic views of the esophageal lesions (a) and the cardial lesions (b), 6 weeks after the initial pacing-related electrical burn.

necrosis, reaching into stomach, were found in the distal anterior and posterior esophageal wall ( $\bullet$ Fig. 1 ). Less severe but circumferential burns affecting the superficial mucosa were found in the entire distal part of the esophagus. Antibiotic therapy and a 2-week course of prednisolone were initiated. The girl recovered over the following weeks and was able to swallow clear liquids and then solids without difficulty. Six weeks later, esophagogastroduodenoscopy showed no esophageal strictures, revealing only well-healed, scarred lesions, without narrowing of the lumen ( $\bullet$ Fig. 2 ). Her myocardial function had completely normalized.

The distal esophagus lies in direct contact with the left atrium and it is therefore used for transesophageal pacing in severe arrhythmias. In adult studies only minimal esophageal injury was reported in a couple of patients after short-term stimulation [1]. In animal studies, transesophageal pacing of 30-minute duration, 2 msec, and 75-100 mA produced minor lesions, but longer pacing times may cause lesions at currents of less than $40 \mathrm{~mA}[2]$.

Transesophageal pacing can be a life-saving procedure but it has to be kept in mind that prolonged stimulation carries a risk of significant esophageal injury, and follow-up endoscopy should be considered.

\section{Endoscopy_UCTN_Code_CPL_1AH_2AK}

\section{H. Köhler ${ }^{1}$, S. Zink ${ }^{2}$, J. Scharf ${ }^{3}$, A. Koch ${ }^{2}$}

${ }^{1}$ Division of Gastroenterology, Kinderund Jugendklinik, Universitätsklinikum Erlangen, Erlangen, Germany

2 Department of Cardiology, Kinderund Jugendklinik, Universitätsklinikum Erlangen, Erlangen, Germany

${ }^{3}$ Intensive Care Unit, Kinder- und Jugendklinik, Universitätsklinikum Erlangen, Erlangen, Germany

\section{References}

1 Santini M, Pandozi C, Colivicchi F et al. Transesophageal low-energy cardioversion of atrial fibrillation: results with the oesophageal-right atrial lead configuration. Eur Heart J 2000; 21: $848-855$

2 Arzbaecher R, Jenkins JM. A review of the theoretical and experimental bases of transesophageal atrial pacing. J Electrocardiol 2002; 35 (Suppl): 137-141

Bibliography

DOI $10.1055 / \mathrm{s}-2007-966611$

Endoscopy 2007; 39: E300

(c) Georg Thieme Verlag KG Stuttgart · New York . ISSN 0013-726X

Corresponding author

\section{H. Köhler, MD}

Kinder- und Jugendklinik

Universitätsklinikum Erlangen

Loschgestraße 15

91054 Erlangen

Germany

Fax: +49-9131-85-33113

henrik.koehler@kinder.imed.uni-erlangen.de 